\title{
Semana de la Música
}

Por Emmy Ruvalcaba Olivarría

Universidad de Sonora

Alumna de la Licenciatura en Música

ruvalcabaemmy@gmail.com
Es una alegría ver cómo los alumnos/as de la Licenciatura en Música están buscando hacer algo más que sólo concentrarse en el estudio de su instrumento ya que, como alumna de canto de octavo semestre de esta carrera, sentía que algo hacía falta en nuestra escuela, algo que nos uniera más, no solo como compañeros de clase, también como amantes de la música y del conocimiento de todo lo que la rodea, ya que cada vez nos damos cuenta de la importancia de la investigación en nuestra área lo que nos hace músicos más completos.

Había visto antes cómo en otras carreras se organizan eventos, como por ejemplo el MARTesDANZA por la Licenciatura en Artes Escénicas, opción Danza o la Semana de Arquitectura y Diseño Gráfico, los cuales se celebran anualmente. En la Licenciatura en Música se suelen impartir cursos de cada instrumento, como por ejemplo, el Curso de Repertorio Vocal de la pianista Teresa Rodríguez, quien desde hace siete años, ha estado con nosotros cada octubre y nos ha enriquecido con sus conocimientos como coach vocal, también ha habido cursos de piano impartidos por el pianista Abdiel Vázquez y cursos de guitarra impartidos por guitarristas como Arody García y Joaquín Clerch. Pero en realidad no teníamos algún evento dirigido y realizado por el estudiantado sin importar el instrumento.

La primera edición de la Semana de la Música fue organizada por Denisse Campoy (organizadora general), Mariana Ortega (tesorera), Ivanna Gómez (logísti- ca) y César Quijada (encargado de staff), que a su vez conforman la Sociedad de Alumnos/as de Música de la Universidad de Sonora. El evento se llevó a cabo los días del 20 al 24 de noviembre del 2018, en celebración del día del músico el día 22 del mismo mes. Los preparativos fueron rápidos, pero eso no impidió que los organizadores nos brindaran un programa de primera, pues constó de conferencias, paneles, conciertos y hasta debates con temas de interés general del alumnado, los cuales se llevaron a cabo en el SUM de nuestro edificio.

El programa corrió de la siguiente manera: el día martes 20 de noviembre se inaugura el evento a las 9:00 horas, contando con la presencia de distinguidas autoridades de la División de Humanidades y Bellas Artes, la Jefatura del Departamento de Bellas Artes y la Coordinación del programa de Licenciatura en Música seguido del primer panel titulado "Panorama de la historia del Jazz - Ensamble de Jazz" y concierto didáctico en el cual participaron los exalumnos Edgar Romero, Aaron Lugo y Daniel Fuentevilla. A las 11:30 dio comienzo el segundo panel con el tema de musicología en el que participaron la Dr. Diana Brenscheitd, la Dr. Leticia Varela, la Mtra. Rocío Terán y el Mtro. Felizardo Andrade.

El miércoles 21 comienza el día con un panel de propuestas musicales en Hermosillo conformado por Erick Quijada y Oscar Mayoral, sucedido por la primera conferencia del programa titulada "Inclusión y Conciencia" por el Centro de 
Atención a la Información para personas con Discapacidad Visual (CAIDIV) de la Universidad de Sonora. El último panel del día se trató de la materia de Desarrollo de habilidades en el instrumento, explorando otras posibilidades de la materia, el cual hizo partícipe a todo el personal docente que imparte esta materia.

Las actividades del jueves 22 dieron inicio con una conferencia del Dr. José Garibaldi, con el tema de "Música y Depresión", seguido de otra conferencia titulada "Psico Acústica Musical", en la que la Dra. Leticia Varela nos compartió sus conocimientos acerca del tema. Las actividades del día terminaron con el panel de "Música en México" conformado por David Norzagray y el Mtro. Fernando Serrano.

El viernes 23 comenzó con un panel de Música para puesta en Escena: Música en el teatro, cine y danza, en el cual participaron los ex alumnos Alejandro Karo, Mayra Lepró, el pianista Héctor Acosta y la maestra Adriana Castaños. El segundo y último panel del día fue conformado por Eduardo Ramírez, Marco Antonio Encinas y Raymundo Ochoa con el tema "De la Composición a la Teoría Postonal”.

Además del día del músico, la Primera Edición de la Semana de la Música celebró también los 20 años de la licenciatura por lo que, en el último día del evento, el sábado 24 a las 11:00 horas, se realizó un debate abierto entre el estudiantado y el profesorado de la Licenciatura estando presentes La Dr. Diana Brenscheidt Genannt Jost, el Dr. Leonel De Gunther Delgado, la Dra. Zaruhi Martirosyan, el Dr. Arturo Valencia Ramos, el Dr. Jesús Eduardo Ramírez Paredes, el M.M. Fernando De Jesús Serrano Arias, el M.H. German Mendoza Cota, la M.M. María Del Rocío Terán Diaz Landa y representantes de las diferentes generaciones de estudiantes. El evento fue moderado por el Lic. César Arturo Velázquez. Esa misma tarde se realizó un convivio con escenario abierto donde profesores y alumnos interpretaron piezas sin programa fijo, dando así por finalizado el evento.

La Lic. en Música ha pasado por varios cambios desde que inicié mis estudios, la mayoría de ellos para mejorar la calidad de nuestra escuela y subir el nivel de los alumnos/as, formando así músicos más completos. Un ejemplo de estos cambios ha sido la realización de este evento que se logró llevar a cabo con la idea que cada año se celebre una edición más y esto gracias a los estudiantes que tuvieron la iniciativa y a los maestros que buscan ayudarnos en alcanzar un desarrollo de calidad.

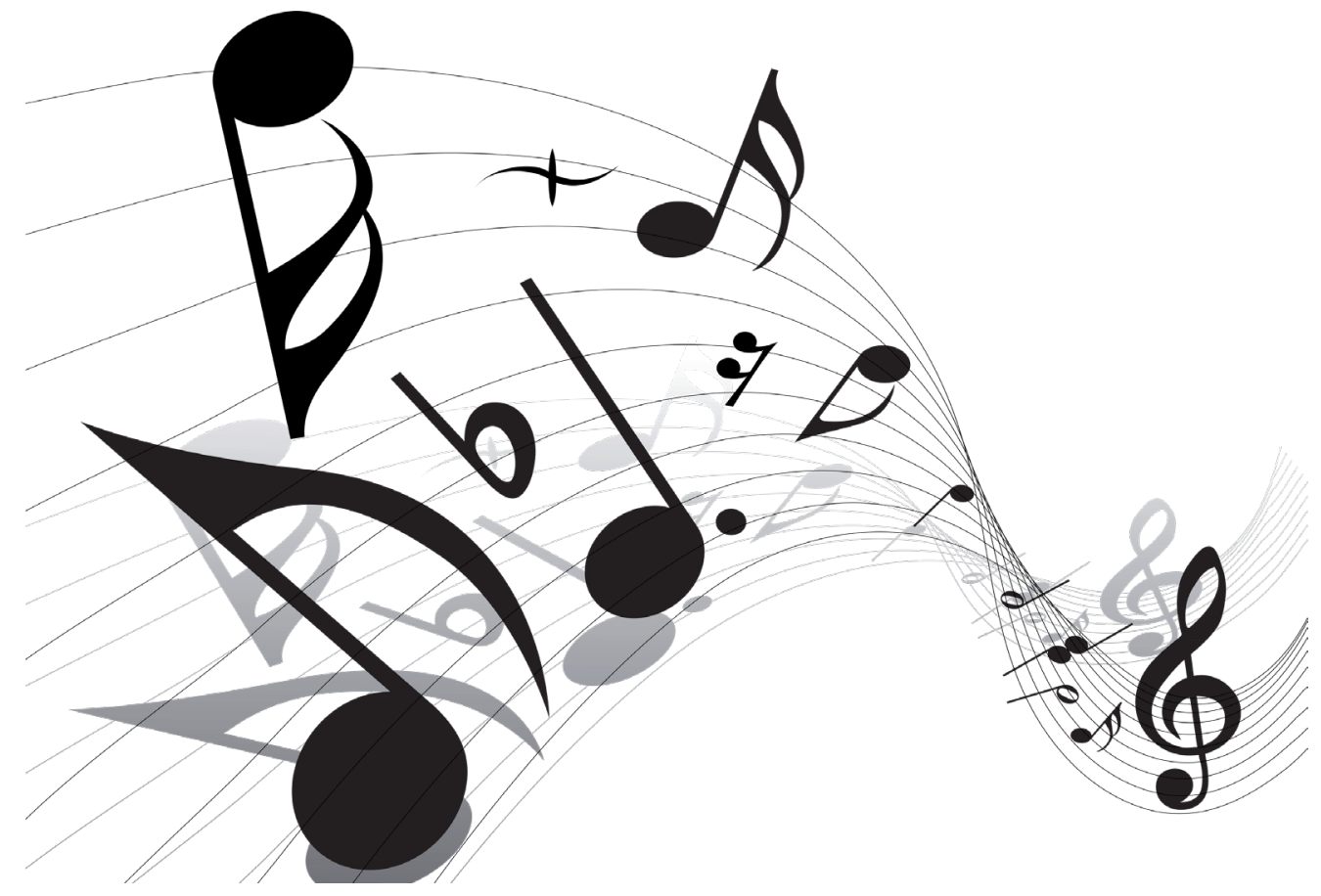

